\title{
Dual Chamber Power Injector
}

National Cancer Institute

\section{Source}

National Cancer Institute. Dual Chamber Power Injector. NCI Thesaurus. Code C110944.

A pump system with two enclosed reservoirs, designed to deliver various concentrations of intravenous contrast media. 